\title{
Repeated administration of caffeine induces either sensitization or tolerance of locomotor stimulation depending on the environmental context
}

\author{
Roberta Zancheta ${ }^{1,2}$, Ana P.M. Possi ${ }^{1,2}$, Cleopatra S. Planeta ${ }^{1,2}$, \\ Marcelo T. Marin ${ }^{1,3}$ \\ ${ }^{1}$ Laboratory of Pharmacology, School of Pharmaceutical Sciences, Univ. Estadual Paulista-UNESP, \\ Rod. Araraquara-Jaú Km 1, 14801-902, Araraquara, SP, Brazil \\ ${ }^{2}$ Interinstitutional Graduate Program in Physiological Sciences, UFSCar/UNESP, Rod. Washington Luiz Km 235, \\ 13565-905, São Carlos, SP, Brazil \\ ${ }^{3}$ Institute of Biomedical Sciences, Federal University of Uberlândia (UFU), Av. Pará 1720, 38400-902, Uberlândia, \\ MG, Brazil
}

Correspondence: Marcelo T. Marin, e-mail: marcelotm@icbim.ufu.br

\begin{abstract}
:
Caffeine is the psychostimulant substance consumed in greatest quantities in the world. The repeated administration of psychostimulants can either decrease or increase the drug effect, inducing tolerance or sensitization, respectively, depending on administration procedure. Not only the dose and regimen, but also the environment where drug is administered, seem to modulate the changes in locomotor activity following repeated psychostimulant administration. The purpose of the present study was to examine the influence of the environmental context on caffeine-induced psychomotor stimulation following repeated administration of this drug. Our results showed that repeated caffeine induced psychomotor sensitization when drug injections were paired with the environment in which the animals were subsequently tested, whereas tolerance occurred when the animals received repeated caffeine in an environment different from that where the tests were performed. In conclusion, the present results demonstrated that the environmental context where caffeine is administered is a key factor modulating the adaptations of the organism to drug effects.
\end{abstract}

Key words:

caffeine, sensitization, tolerance, environmental context, psychostimulants

\section{Introduction}

Caffeine is the psychostimulant substance most commonly used as a regular component of the diet. It is present in coffee, tea, soft drinks, food and medications $[15,16]$. For many centuries, the effects of caffeine in reducing fatigue and increasing wakefulness and alertness have been recognized. Currently, exist- ing nonprescription medications, energy drinks and supplements that contain caffeine add further opportunities for people to consume caffeine as an ergogenic (work-enhancing) aid [6]. In rats, the psychostimulant effect of caffeine can easily be assessed by measuring locomotor activity, which is increased in response to the administration of small to moderate doses of this drug $[17,27,44]$. 
Repeated administration of psychostimulants can either decrease or increase the drug effect, inducing tolerance or sensitization, respectively, depending on the administration procedures used [19, 39]. Administration of caffeine through drinking water generally engenders tolerance of drug-induced locomotor activity [8, 45]. Also, Lau and Falk [24] showed evidence of caffeine tolerance following a long period of daily intraperitoneal (ip) drug injections. Development of tolerance has been related to neuroadaptations responsible for withdrawal symptoms when the repeated administration of psychostimulants is discontinued [29, 41]. In contrast, it has been shown that an $i p$ injection of caffeine on alternate days for two weeks induces sensitization to its psychomotor stimulation [7, 42]. Psychomotor sensitization is a common outcome of chronic administration of psychostimulants, such as amphetamine and cocaine, and has been related to neuroadaptations implicated in drug addiction $[32,33$, 37]. The environment in which drugs are administered modulates the development of psychomotor sensitization to these drugs as well as the subsequent sensitized response [32, 34]. Sensitization to amphetamine or cocaine is easily observed when the drug is injected in an environmental context different from that of the home cage $[4,38]$. Moreover, the sensitization is more robust if the locomotor effects of these drugs are tested in the same context (paired environment) as in previous administrations $[2,25,48]$.

In this study we examined the influence of the environmental context on caffeine-induced behavioral alterations (sensitization and tolerance) following repeated drug treatment. To this end, rats were repeatedly treated with caffeine in the home cage or in an activity box. Locomotor activity in response to caffeine was then tested in the activity box and results were analyzed relating environmental pairing to drug-induced alterations in locomotor activity.

\section{Materials and Methods}

\section{Subjects and drugs}

Subjects were male Wistar rats (180-200 g) obtained from the animal breeding facility of the São Paulo State University - UNESP. Groups of 3-4 animals were housed in plastic cages [32 (width) $\times 40$ (length) $\times 16$ (height) $\mathrm{cm}]$ in a room maintained at $23 \pm 2{ }^{\circ} \mathrm{C}$.
Rats were kept in a 12:12 h light/dark cycle (lights on at 7:00 a.m.) and were allowed free access to food and water. Each animal was used in only one experimental procedure. All experiments were performed during the light phase between 8:00 a.m. and 5:00 p.m., and animals were randomly tested across this time period. The experimental protocol (07/2008) was approved by the Ethical Committee for use of Human or Animal Subjects of the School of Pharmaceutical Sciences UNESP and the experiments were conducted according to the principles of the Brazilian College of Animal Experimentation - (COBEA), based on NIH Guidelines for the Care and Use of Laboratory Animals.

Anhydrous caffeine (Purifarma, São Paulo-SP, Brazil) was diluted in $0.9 \% \mathrm{NaCl}$ (saline) and ip injected at $1 \mathrm{ml} / \mathrm{kg}$.

\section{Behavioral apparatus}

Activity monitoring chamber (Columbus Instruments, Columbus, OH, USA) consisted of a Plexiglas box measuring 44 (width) $\times 44$ (length) $\times 20$ (height) $\mathrm{cm}$. It contained 10 pairs of infrared photocells, which were used to measure the horizontal locomotor activity. The consecutive interruption of two beams was recorded as one unit of locomotion count.

\section{Experiment 1: Caffeine locomotor effect in the environment paired with repeated treatment}

The experiment was based on that of Simola et al. [42, 43] and consisted of two phases: treatment phase, when drug was repeatedly administered, and test phase, when behavior in response to the drug was recorded. The treatment phase lasted 13 days and caffeine was administrated on alternate days (one injection every $48 \mathrm{~h}$; total of seven injections). On each day of drug administration, rats were transported in their home cages from the animal facility to a nearly room, where they were kept for 40 min, after which they received ip injections of caffeine $(15 \mathrm{mg} / \mathrm{kg})$ or saline and were placed in the activity monitoring chamber for $20 \mathrm{~min}$. The floor and walls of the chamber were cleaned with $70 \%$ ethanol and dried with paper towels between each rat exposure. Three days after the last scheduled administration of caffeine or saline, the test phase was performed. First, the rats were transported from the animal facility to the room where the treatment was performed as described above. Next, rats were individually placed in the activity- 
monitoring chamber and left for $30 \mathrm{~min}$ for habituation. Following this period, rats received ip injections of caffeine $(10 \mathrm{mg} / \mathrm{kg})$ or saline and returned to the activity monitoring-chamber for another $30 \mathrm{~min}(\mathrm{n}=$ 9-10 animals per group). Locomotor activity was recorded during the $30 \mathrm{~min}$ of habituation and also in each 5-min interval following the caffeine or saline injection.

The $10 \mathrm{mg} / \mathrm{kg}$ test dose of caffeine was chosen on the basis of previous dose-effect studies performed in our laboratory. This dose increased locomotor activity but produced a sub-maximal effect [27].
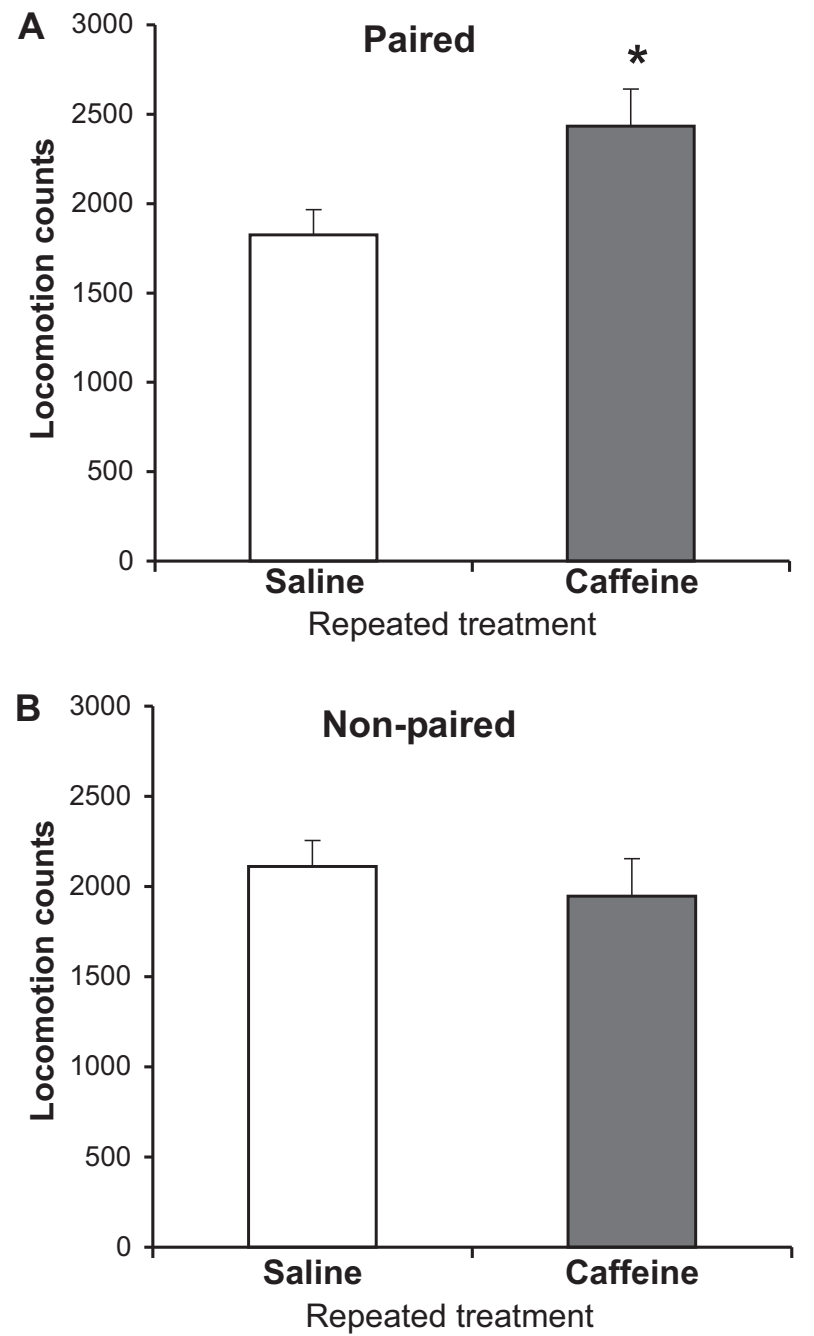

Fig. 1. Locomotor activity during habituation in the paired $(\mathbf{A})$ or nonpaired $(\mathbf{B})$ environments. Data represent the mean \pm SEM of locomotor activity accumulated in $30 \mathrm{~min}$ in the activity box ( $n=16-19$ animals per group); * $p<0.05$ compared to the repeated saline treatment group (Student's t-test)

\section{Experiment 2: Caffeine locomotor effect in the environment not paired with the repeated treatment}

This experiment consisted of two phases as described in Experiment 1. However, during the treatment phase rats received repeated injections of caffeine (15 $\mathrm{mg} / \mathrm{kg}$, ip) or saline immediately after their removal from their home cages in the animal facility. After the injections, animals were returned to their home cages. Thus, in this experiment rats received the same drug treatment as previously, but were never exposed to the environment (activity monitoring chamber) in which caffeine-induced locomotor activity was tested $(\mathrm{n}=8$ animals per group).

\section{Statistical analyses}

The habituation data were analyzed by Student' $s$-test for independent samples, comparing caffeine and saline treatments. The behavioral data after the caffeine test injection were first analyzed by three-way ANOVA, considering the factors: treatment (saline $\times$ caffeine $15 \mathrm{mg} / \mathrm{kg}$ ), test (saline $\times$ caffeine $10 \mathrm{mg} / \mathrm{kg}$ ) and time ( $5 \mathrm{~min}$ intervals during $30 \mathrm{~min}$ session, repeated variable). As the time factor did not display significant interaction with treatment or test, the total locomotion count during the 30-min session was further analyzed by two-way ANOVA, for only the treatment and test factors. In cases where ANOVA showed significant differences $(\mathrm{p}<0.05)$, the results were analyzed by the Newman-Keuls post-hoc test, to check the differences between pairs of groups.

\section{Results}

\section{Habituation to test environment}

The Student $t$-test for locomotor activity during the habituation period prior to injections showed that rats repeatedly treated with caffeine in the same environment as the test (activity chamber) showed higher locomotion counts than rats treated with saline $(\mathrm{t}=$ $-2.17 ; \mathrm{p}<0.05)$. However, rats repeatedly treated with caffeine in the home cages did not show enhanced locomotor activity in the activity chamber compared to saline group $(t=1.03 ; p=0.31)($ Fig. 1$)$. 


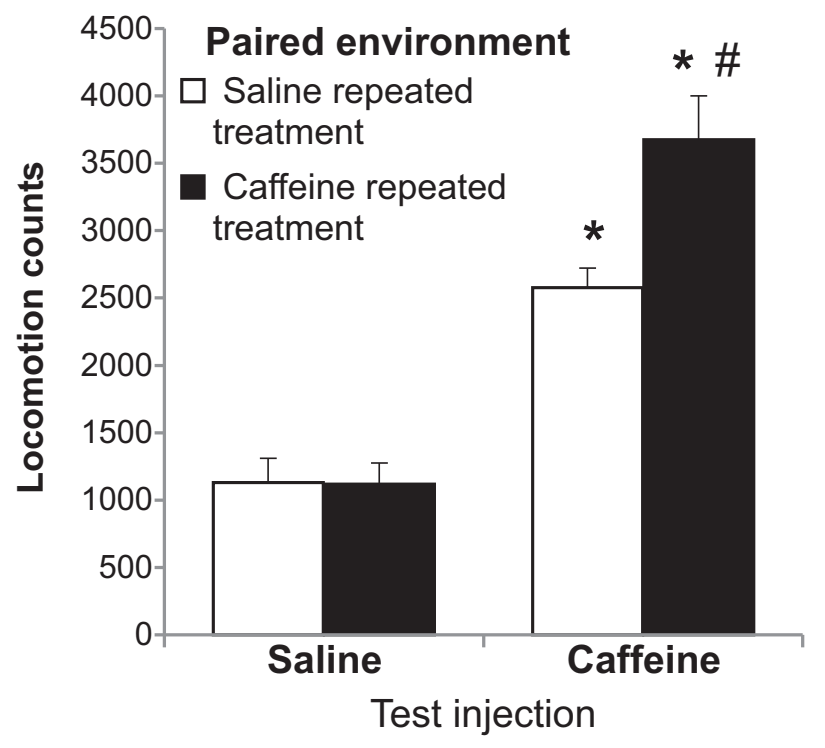

Fig. 2. Caffeine locomotor effect in the environment paired with repeated treatment. Data represent the mean \pm SEM of locomotor activity accumulated during 30 min following ip injection of caffeine (10 mg/kg) or saline ( $n=9-10$ animals per group); * $p<0.001 \mathrm{com}-$ pared to saline test injection and the same repeated treatment, \# $p<$ 0.01 compared to caffeine test injection after repeated saline (Newman Keuls' test)

\section{Caffeine locomotor effect in the environment paired with repeated treatment}

Two-way ANOVA on total locomotor counts in the $30 \mathrm{~min}$ session revealed significant differences for treatment $[\mathrm{F}(1,34)=6.01 ; \mathrm{p}<0.05]$ and test $[\mathrm{F}(1,34)=81.83$; $\mathrm{p}<0.001]$ factors. In addition, a significant interaction was detected between treatment and test factors $[\mathrm{F}(1,34)=6.31 ; \mathrm{p}<0.01]$. The Newman-Keuls test revealed that caffeine test injection increased the locomotor activity in rats that had been repeatedly treated with saline or caffeine $(p<0.001)$. Moreover, rats repeatedly treated with caffeine displayed increased locomotor activity following the caffeine test injection ( $\mathrm{p}<0.01)$, suggesting the presence of locomotor sensitization when the test was performed in the environment paired with the repeated treatment (Fig. 2).

\section{Caffeine locomotor effect in the environment not paired with repeated treatment}

Two-way ANOVA on total locomotor counts in the 30 min session revealed significant differences for

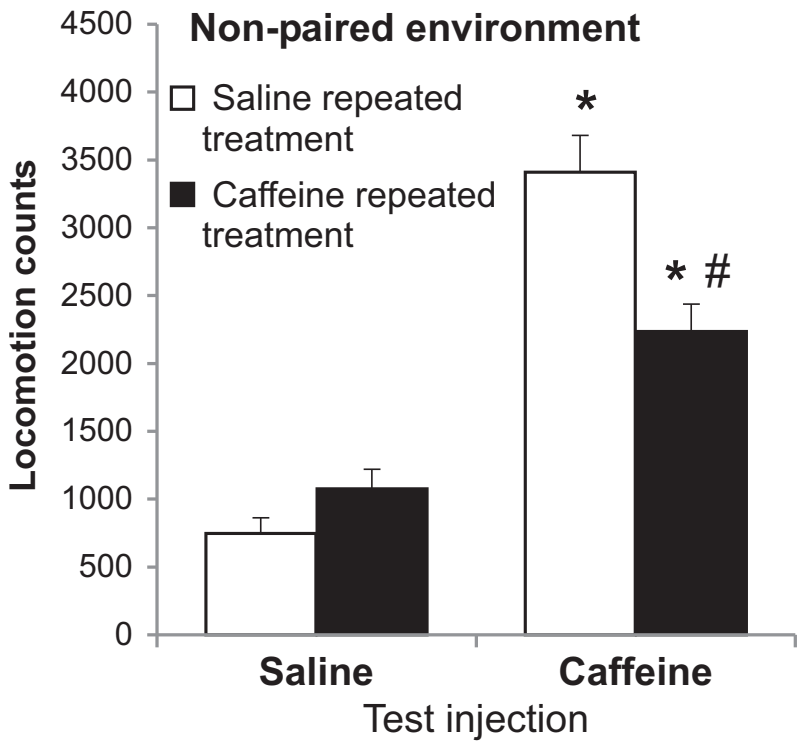

Fig. 3. Caffeine locomotor effect in the environment non-paired with repeated treatment. Data represent the mean \pm SEM of locomotor activity accumulated during $30 \mathrm{~min}$ following ip injection of caffeine (10 mg/kg) or saline ( $n=8$ animals per group); * $p<0.001$ compared to saline test injection and the same repeated treatment, $\# p<0.001$ compared to caffeine test injection after repeated saline (Newman Keuls' test)

treatment $[\mathrm{F}(1,27)=4.80 ; \mathrm{p}<0.05]$ and test $[\mathrm{F}(1,27)=98.22 ; \mathrm{p}<0.001]$ factors. Also, a significant interaction was detected between treatment and test $[\mathrm{F}(1,27)=15.19 ; \mathrm{p}<0.001]$. The Newman-Keuls post-hoc test revealed that caffeine challenge increased the locomotor activity in rats that were previously treated with either saline or caffeine $(p<0.001)$. Moreover, caffeine-induced locomotor activity was lower in the rats repeatedly treated with caffeine than in those repeatedly treated with saline $(p<0.001)$, suggesting the presence of tolerance to the locomotor effect of caffeine when the test was performed in the environment not paired with the repeated treatment (Fig. 3).

\section{Discussion}

Chronic administration of drugs of abuse results in neuroadaptations that can be expressed as behavioral sensitization or tolerance [37]. It has been clearly demonstrated that repeated intermittent injections of 
psychostimulants such as cocaine or amphetamine produce an enhanced locomotor response to a subsequent injection of the drug; a phenomenon generally termed behavioral sensitization $[18,26,28]$. Interestingly, whereas repeated daily ip injections of cocaine (15 $\mathrm{mg} / \mathrm{kg}$ ) induce psychomotor sensitization, the continuous administration of this drug at the same dose per day by osmotic pump produces tolerance [19]. Besides the dose and regimen of drug administration, the environment in which the drug is given seems to modulate the changes in locomotor activity following repeated psychostimulants $[32,34]$. Our results showed that administration of $15 \mathrm{mg} / \mathrm{kg}$ of caffeine caused behavioral sensitization when the injections were performed in the same environment as that where the animals were subsequently tested (3 days after the last injection). Similarly, Simola et al. [42, 43] showed that rats treated with $15 \mathrm{mg} / \mathrm{kg}$ of caffeine (ip) on alternate days, i.e., one injection every other day, for 14 days (seven administrations in total) showed an enhanced locomotor response when challenged with caffeine or amphetamine in the same context in which these drugs had been repeatedly administered.

The environment in which the drug is administered strongly regulates the behavioral alterations of other psychostimulant treatments. In this sense, it has been demonstrated that amphetamine or cocaine challenge injections in a novel environment, different from the home cage, produce a more robust behavioral sensitization than drug administration in the home cage [4, $5,14]$. It is hypothesized that learned associations develop between drug effects and contextual stimuli during repeated drug administration, to produce a form of sensitization called context-specific sensitization [2, $11,25]$. Our results showed that, similarly to amphetamine and cocaine, caffeine psychomotor sensitization is modulated by the environmental context of the administration.

The neuroadaptations related to behavioral sensitization have been implicated in the development of drug addiction and also in the relapse to drug-seeking behavior $[10,22,31,36]$. Considering that caffeine behavioral effects are sensitized when the drug is tested in the same environment as the repeated treatment, this drug induces a similar process observed to other psychostimulant drugs. This result corroborates other studies suggesting that caffeine might induce addiction because its consumption fulfils some of the criteria for drug addiction and it shares some specific types of action, such as behavioral sensitization, with amphetamine and cocaine [21, 30]. However, Satel [40] supports the view that caffeine consumption patterns are too inconsistent to describe it as addictive.

This study also showed that spontaneous locomotor activity during habituation period in the environment previously paired with the repeated injections was higher in caffeine- than saline-pretreated rats. This effect occurs possibly because of the development of a conditioned response to the activity box resulting from pairing injections to this environment. This hypothesis is corroborated by the observation that an increase in locomotion during habituation did not occur in the animals that received caffeine or saline in their home cages (not paired groups). Interestingly, this conditioned response did not appear following saline injections in the test day, indicating that it was restricted to the first $30 \mathrm{~min}$ in the environment and did not interfere with the heightened caffeine response.

Our data also demonstrated that caffeine administrated by the same route, dose and schedule, but in an environment distinct from the one where the animals were tested, produced tolerance to its locomotor effect. The expression of tolerance when caffeine was tested in the environment not paired with the repeated treatment is similar to that observed by Aquas et al. [1]. They revealed tolerance to caffeine-induced locomotion after caffeine injections $(25 \mathrm{mg} / \mathrm{kg}$, ip, twice daily) for 7 days in the home cages. In addition, tolerance to the psychostimulant effect of caffeine is generally observed when this drug is administrated through drinking water $[8,45]$, subcutaneous minipumps [23] or a long period of daily ip injections [24]. These studies and the present data have in common the fact that tolerance to caffeine psychomotor stimulation seems to be evident when environmental cues during the test session are not the same as those present during the repeated treatment.

Drug tolerance following the repeated administration of drugs of abuse can result from neuroadaptations that are related to the withdrawal syndrome seen when the drug is discontinued [29, 37]. In rodents, common effects of caffeine withdrawal are decreased locomotor activity and reinforcement threshold for electrical brain stimulation [23, 30]. Withdrawal syndrome in humans comprises a variety of symptoms, including apathy, weakness, headaches, anxiety, decreased motor behavior, tremor and nausea [16]. Caffeine dose administered in the test injections $(10 \mathrm{mg} / \mathrm{kg}$ ) to rats correspond to about 2 to 3 cups of coffee in human weighing $70 \mathrm{~kg}$ [16]. 
Caffeine is predominantly an adenosine $\mathrm{A}_{1}$ and $\mathrm{A}_{2 \mathrm{~A}}$ receptor antagonist on doses generally consumed by humans $[3,46]$. The antagonism of adenosine receptors mediates alterations in the mesocorticolimbic dopaminergic system that is associated to the psychomotor effects of caffeine $[12,13]$. It has been demonstrated in microdialysis studies that systemic administration of moderate doses of caffeine $(10-30 \mathrm{mg} / \mathrm{kg}$, ip) increases extracellular levels of dopamine in the nucleus accumbens of rats [44]. However, De Luca et al. [9] showed that similar doses of caffeine increase extracellular levels of dopamine preferentially in the medial prefrontal cortex and not in the nucleus accumbens. Caffeine locomotor sensitization has been associated with a decreased $\mathrm{A}_{2 \mathrm{~A}}$ receptor in the nucleus accumbens [47], a sensitized response to dopaminergic indirect agonists [7, 42] and increased dopamine tissue levels in the striatum [20]. Caffeine tolerance is associated with decreased binding sites on the $\mathrm{A}_{1}$ adenosine receptor and increased binding on the same receptor during withdrawal $[8,23]$. Also, caffeine tolerance is accompanied by decreased $\mathrm{D}_{1}$ dopamine receptors binding sites in the nucleus accumbens and caudate putamen [35]. Thus, we can hypothesize that environmental context might modulate the alterations on adenosinergic and dopaminergic neurotransmission systems related to sensitization or tolerance of caffeine locomotor effect after repeated drug administration.

\section{Conclusion}

In our study, we demonstrated that caffeine, administered by the same route, dose and schedule, induced opposite behavioral adaptations following repeated treatment, depending on the environmental context of treatment. This highlights the key modulation of the outcome of chronic caffeine administration by the environment surrounding the drug treatment.

\section{Acknowledgments:}

This work was supported by Fundação de Amparo à Pesquisa do Estado de São Paulo (FAPESP) fellowships to RZ (07/57542-9), APMP (07/57541-2) and MTM (08/10892), and grant to CSP (08/01744-5). CSP is a CNPq Research Fellow.

\section{References:}

1. Acquas E, Tanda G, Di Chiara G: Differential effects of caffeine on dopamine and acetylcholine transmission in brain areas of drug-naive and caffeine-pretreated rats. Neuropsychopharmacology, 2002, 27, 182-193.

2. Anagnostaras SG, Robinson TE: Sensitization to the psychomotor stimulant effects of amphetamine: modulation by associative learning. Behav Neurosci, 1996, 110, 1397-1414.

3. Antoniou K, Papadopoulou-Daifoti Z, Hyphantis T, Papathanasiou G, Bekris E, Marselos M, Panlilio L et al.: Detailed behavioral analysis of the acute motor effects of caffeine in the rat: involvement of adenosine $\mathrm{A}_{1}$ and $\mathrm{A}_{2 \mathrm{~A}}$ receptors. Psychopharmacology (Berl), 2005, 183, 154-162.

4. Badiani A, Anagnostaras SG, Robinson TE: The development of sensitization to the psychomotor stimulant effects of amphetamine is enhanced in a novel environment. Psychopharmacology (Berl), 1995, 117, 443-452.

5. Browman KE, Badiani A, Robinson TE: The influence of environment on the induction of sensitization to the psychomotor activating effects of intravenous cocaine in rats is dose-dependent. Psychopharmacology (Berl), 1998, 137, 90-98.

6. Burke LM: Caffeine and sports performance. Appl Physiol Nutr Metab, 2008, 33, 1319-1334.

7. Cauli O, Pinna A, Valentini V, Morelli M: Subchronic caffeine exposure induces sensitization to caffeine and cross-sensitization to amphetamine ipsilateral turning behavior independent from dopamine release. Neuropsychopharmacology, 2003, 28, 1752-1759.

8. Chou DT, Khan S, Forde J, Hirsh KR: Caffeine tolerance: Behavioral, electrophysiological and neurochemical evidence. Life Sci, 1985, 36, 2347-2358.

9. De Luca MA, Bassareo V, Bauer A, Di Chiara G: Caffeine and accumbens shell dopamine. J Neurochem, 2007, 103, 157-163.

10. De Vries TJ, Schoffelmeer AN, Binnekade R, Mulder $\mathrm{AH}$, Vanderschuren LJ: Drug-induced reinstatement of heroin- and cocaine-seeking behaviour following longterm extinction is associated with expression of behavioural sensitization. Eur J Neurosci, 1998, 10, 3565-3571.

11. Duvauchelle CL, Ikegami A, Asami S, Robens J, Kressin K, Castaneda E: Effects of cocaine context on NAcc dopamine and behavioral activity after repeated intravenous cocaine administration. Brain Res, 2000, 862, 49-58.

12. El Yacoubi M, Ledent C, Meânard JF, Parmentier M, Costentin J, Vaugeois JM: The stimulant effects of caffeine on locomotor behavior in mice are mediated through its blockade of adenosine $\mathrm{A}_{2 \mathrm{~A}}$ receptors. $\mathrm{Br}$ J Pharmacol, 2000, 129, 1465-1473.

13. Fisione G, Borgkvist A, Usiello A: Caffeine as a psychomotor stimulant: mechanism of action. Cell Mol Life Sci, 2004, 61, 857-872.

14. Fraioli S, Crombag HS, Badiani A, Robinson TE: Susceptibility to amphetamine-induced locomotor sensitization is modulated by environmental stimuli. Neuropsychopharmacology, 1999, 20, 533-541. 
15. Frary CD, Johnson RK, Wang MQ: Food sources and intakes of caffeine in the diets of persons in the United States. J Am Diet Assoc, 2005, 105, 110-113.

16. Fredholm BB, Battig K, Holmen J, Nehlig A, Zvartau EE: Actions of caffeine in the brain with special reference to factors that contribute to its widespread use. Pharmacol Rev, 1999, 51, 83-133.

17. Halldner L, Adén U, Dahlberg V, Johansson B, Ledent $\mathrm{C}$, Fredholm BB: The adenosine $\mathrm{A}_{1}$ receptor contributes to the stimulatory, but not the inhibitory effect of caffeine on locomotion: a study in mice lacking adenosine $\mathrm{A}_{1}$ and/or $\mathrm{A}_{2 \mathrm{~A}}$ receptors. Neuropharmacology, 2004, 46, 1008-1017.

18. Heidbreder CA, Thompson AC, Shippenberg TS: Role of extracellular dopamine in the initiation and long-term expression of behavioral sensitization to cocaine. J Pharmacol Exp Ther, 1996, 278, 490-502.

19. Hope BT, Crombag HS, Jedynak JP, Wise RA: Neuroadptations of total levels of adenylate cyclase, protein kinase A, tyrosine hydroxylase, cdK5 and neurofilaments in the nucleus accumbens and ventral tegmental area do not correlate with expression of sensitized or tolerant locomotor responses to cocaine. J Neurochem, 2005, 92, 536-545.

20. Hsu CW, Wang CS, Chiu TH: Caffeine and a selective adenosine $\mathrm{A}_{2 \mathrm{~A}}$ receptor antagonist induce sensitization and cross-sensitization behavior associated with increased striatal dopamine in mice. J Biomed Sci, 2010, $17,1-10$.

21. Hughes JR, Oliveto AH, Liguori A, Carpenter J, Howard T: Endorsement of DSM-IV dependence criteria among caffeine users. Drug Alcohol Depend, 1998, 52, 99-107.

22. Kalivas PW, Pierce RC, Cornish J, Sorg BA: A role for sensitization in craving and relapse in cocaine addiction. J Psychopharmacol, 1998, 12, 49-53.

23. 23. Kaplan GB, Greenblatt DJ, Kent MA, Cotreau-Bibbo MM: Caffeine treatment and withdrawal in mice: relationships between dosage, concentrations, locomotor activity and $\mathrm{A}_{1}$ adenosine receptor binding. J Pharmacol Exp Ther, 1993, 266, 1563-1572.

24. Lau CE, Falk JL: Dose-dependent surmountability of locomotor activity in caffeine tolerance. Pharmacol Biochem Behav, 1995, 52, 139-143.

25. Marin MT, Berkow A, Golden SA, Koya E, Planeta CS, Hope BT: Context-specific modulation of cocaineinduced locomotor sensitization and ERK and CREB phosphorylation in the rat nucleus accumbens. Eur J Neurosci, 2009, 30, 1931-1940.

26. Marin MT, Cruz FC, Planeta CS: Cocaine-induced behavioral sensitization in adolescent rats endures until adulthood: Lack of association with GluR1 and NR1 glutamate receptor subunits and tyrosine hydroxylase. Pharmacol Biochem Behav, 2008, 91, 109-114.

27. Marin MT, Zancheta R, Paro AH, Possi APM, Cruz FC, Planeta CS: Comparison of caffeine-induced locomotor activity between adolescent and adult rats. Eur J Pharmacol, 2011, 660, 363-367.

28. Mattson BJ, Crombag HS, Mitchell T, Simmons DE, Kreuter JD, Morales M, Hope BT: Repeated amphetamine administration outside the home cage enhances drug-induced Fos expression in rat nucleus accumbens. Behav Brain Res, 2007, 185, 88-98.

29. Mumford GK, Neill DB, Holtzman SG: Caffeine elevates reinforcement threshold for electrical brain stimulation: tolerance and withdrawal changes. Brain Res, 1988, 459, 163-167.

30. Nehlig A: Are we dependent upon coffee and caffeine? A review on human and animal data. Neurosc Biobehav Rev, 1999, 23, 563-576.

31. Nestler EJ: Molecular basis of long-term plasticity underlying addiction. Nat Rev Neurosci, 2001, 2, 119-128.

32. Post RM, Lockfeld A, Squillace, KM, Contel NR: Drug-environment interaction: context dependency of cocaine-induced behavioral sensitization. Life Sci, 1981, 28, 755-760.

33. Post RM, Rose H: Increasing effects of repetitive cocaine administration in the rat. Nature, 1976, 260, 731-732.

34. Post RM, Weiss SR, Fontana D, Pert A: Conditioned sensitization to the psychomotor stimulant cocaine. Ann NY Acad Sci, 1992, 654, 386-399.

35. Powell KR, Iuvone PM, Holtzman SG: The role of dopamine in the locomotor stimulant effects and tolerance to these effects of caffeine. Pharmacol Biochem Behav, 2001, 69, 59-70.

36. Robinson TE, Berridge KC: Addiction. Annu Rev Psychol, 2003, 54, 25-53.

37. Robinson TE, Berridge KC: The neural basis of drug craving: an incentive-sensitization theory of addiction. Brain Res Brain Res Rev, 1993, 18, 247-291.

38. Robinson TE, Browman KE, Crombag HS, Badiani A: Modulation of the induction or expression of psychostimulant sensitization by the circumstances surrounding drug administration. Neurosci Biobehav, 1998, 22, 347-354.

39. Sanchis-Segura C, Spanagel R: Behavioural assessment of drug reinforcement and addictive features in rodents: an overview. Addict Biol, 2006, 11, 2-38.

40. Satel S: Is caffeine addictive? A review of the literature. Am J Drug Alcohol Abuse, 2006, 32, 493-502.

41. Sigmon SC, Herning RI, Better W, Cadet JL, Griffiths RR: Caffeine withdrawal, acute effects, tolerance, and absence of net beneficial effects of chronic administration: cerebral blood flow velocity, quantitative EEG, and subjective effects. Psychopharmacology (Berl), 2009, 204, 573-585.

42. Simola N, Cauli O, Morelli M: Sensitization to caffeine and cross-sensitization to amphetamine: Influence of individual response to caffeine. Behav Brain Res, 2006, $172,72-79$.

43. Simola N, Tronci E, Pinna A, Morelli M. Subchronic intermittent caffeine amplifies the motor effects of amphetamine in rats. Amino Acids, 2006, 31, 359-363.

44. Solinas M, Ferré S, You ZB, Karcz-Kubicha M, Popoli P, Goldberg SR: Caffeine induces dopamine and glutamate release in the shell of the nucleus accumbens. J Neurosci, 2002, 22, 6321-6324.

45. Svenningsson P, Nomikos GG, Fredholm BB: The stimulatory action and the development of tolerance to caffeine is associated with alterations in gene expression in specific brain regions. J Neurosci, 1999, 19, 4011-4022. 
46. Svenningsson P, Nomikos GG, Ongini E, Fredholm BB: Antagonism of adenosine $\mathrm{A}_{2 \mathrm{~A}}$ receptors underlies the behavioural activating effect of caffeine and is associated with reduced expression of messenger RNA for NGFI-A and NGFI-B in caudate-putamen and nucleus accumbens. Neuroscience, 1997, 79, 753-764.

47. Tronci E, Simola N, Carta AR, De Luca MA, Morelli M: Potentiation of amphetamine-mediated responses in caffeine-sensitized rats involves modifications in $\mathrm{A} 2 \mathrm{~A}$ receptors and zif-268 mRNAs in striatal neurons. J Neurochem, 2006, 98, 1078-1089.

48. Vezina P, Leyton M: Conditioned cues and the expression of stimulant sensitization in animals and humans. Neuropharmacology, 2009, 56, 160-168.

Received: May 12, 2011; in the revised form: September 12 2011; accepted: September 29, 2011. 